\title{
Transcription Symbols
}

The transcription symbols used for the oral, conversational texts in this book are as follows (adapted from Button and Lee 1987: 9-17):

// overlapping utterances ([ ] is another common symbol, but not used here)

$=$ continuous utterances

: extension or prolongation of a sound

$:$ longer extension

? rising intonation

! animated tone

$>$ delivery at a quicker pace than the surrounding talk

(()) editorial comments, transcriptionist's description

hh hh, heh, he, huh laughter

, continuing intonation

. stopping fall in intonation

Numbers in parentheses mark the seconds and tenths of seconds of timed intervals within an utterance or between utterances

(.) a micro-pause that is less than 0.1 seconds

.. a pause of less than $0.1-0.5$ seconds

... a pause greater than 0.5 seconds

- $\quad$ an abrupt cut-off or self-interruption of the sound in progress

An arrow is placed in front of the speaker designation to draw the reader's attention to an utterance. Underlining serves the same purpose.

The above symbols are only a modest sample of the sum of symbols that figure in conversation analytic transcripts in the literature. 